
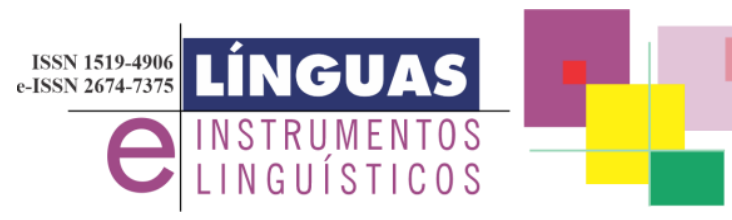

DOI: $10.20396 /$ lil.v24i48.8665513

\title{
Pesquisas em linguagem comprometidas com a educação
}

\section{Language research committed to education}

\author{
Gustavo Santos de Macedo* \\ UNEMAT
}

\section{Albina Pereira de Pinho Silva** \\ UNEMAT}

\begin{abstract}
Resumo: Nesta resenha, são apresentados os artigos que compõem a obra "Estudos da linguagem e compromisso social”, publicada pela Pontes Editora e com organização de Silmara Dela Silva e Mônica Maria Guimarães Savedra. A coletânea é resultado de pesquisas desenvolvidas no Programa de Doutorado Interinstitucional (Dinter), da Universidade Federal Fluminense (UFF). A linguagem é tema central dos estudos, aliada ao compromisso de promover junto aos leitores uma reflexão e atuação crítica diante dos diversos contextos sociais de uso da língua.
\end{abstract}

Palavras-chave: Pesquisas em linguagem, Contexto social, Educação.

Abstract: In this review are presented papers that compose the book entitled "Estudos da linguagem e compromisso social", published by Pontes Editora and organized by Silmara Dela Silva and Mônica Maria Guimarães Savedra. The compilation of articles results from research developed in the Interinstitutional Doctorate Program (Dinter) at the Fluminense Federal University (UFF). Language is the primary subject matter of the studies, coupled with the commitment to promote 
alongside readers a critical reflection and action faced of multiple social contexts of language use.

Keywords: Language research, Social context, Education.

Publicada em 2020 pela Editora Pontes, em meio ao contexto pandêmico da Covid-19, a obra Estudos de linguagem e compromisso social é uma seleção de artigos frutos de pesquisas desenvolvidas no Programa de Doutorado Interinstitucional (Dinter), promovido pelo Programa de Pós-graduação em Estudos da Linguagem da Universidade Federal Fluminense (PosLing - UFF) em parceria com o Instituto de Federal de Educação, Ciência e Tecnologia do Sudeste de Minas Gerais (IF Sudeste MG). Organizada por Silmara Dela Silva e Mônica Maria Guimarães Savedra, a obra reforça a necessidade de se buscar a compreensão sistemática da linguagem, que emerge na/pela pesquisa, para a intervenção responsável no contexto social.

A obra, prefaciada por Frederico Souzalima Caldonceli Franco, à época o Pró-reitor de Pesquisa, Pós-graduação e Inovação do IF Sudeste MG, é composta por 12 capítulos e reúne pesquisas de recentes doutores do Programa de Doutorado Interinstitucional (Dinter) e de alguns convidados, em especial, Mónica Zoppi Fontana e Marcos Bagno. Essa coletânea apresenta diálogos entre diferentes abordagens teóricas, tendo como ponto central a linguagem, ao estabelecer, nas palavras de Frederico Franco, "interfaces que permeiam a comunidade acadêmica e os arredores sociais na Zona da Mata e Campos das Vertentes, em Minas Gerais" (SILVA; SAVEDRA, 2020, p. 7), sem perder de vista o retorno das pesquisas que, em maior ou menor grau, respondem aos anseios dos sujeitos que ali habitam.

O referido Dinter, proposto em 2014 pelo IF Sudeste MG e o PosLing - UFF, e aprovado pela Coordenação de Aperfeiçoamento de Pessoal de Nível Superior (CAPES), teve como principal finalidade a "ampliação do quadro de servidores do Instituto qualificados em nível de doutorado, e o consequente desenvolvimento institucional no campo dos Estudos da Linguagem, na área de Linguística" (SILVA; SAVEDRA, 2020, p. 11), de acordo com as organizadoras da obra.

Mesmo com os diversos cortes feitos pelo Ministério da Educação (MEC), nos últimos anos, quanto ao financiamento das pesquisas em 
nosso país - tema, inclusive, problematizado em um dos artigos desta coletânea - e os recentes ataques à produção científica no momento de sua publicação; a leitura dessa obra já se mostra um primeiro passo do compromisso social proposto pelas autoras e autores desse projeto, especialmente aos estudiosos da (língua)gem. Para além disso, evidencia o comprometimento do Dinter no aperfeiçoamento profissional dos professores universitários envolvidos e fortalece o diálogo entre as instituições de ensino superior atreladas para, com isso, maximizar a pesquisa em linguagem, com destaque na necessidade de reflexão sobre os diversos contextos que a permeiam.

Dividida em duas partes, a obra apresenta uma "pluralidade teórica e temática dos trabalhos reunidos [...] aliada à relevância científica e ao impacto social das pesquisam da quais derivam" (SILVA; SAVEDRA, 2020, p. 18). Na primeira parte, intitulada Estudos do texto e do discurso, as pesquisas se voltam à Análise do Discurso, mais precisamente à semântica global, semiótica discursiva e análises etnometodológica e sociointeracional. São seis textos que denunciam o poder dos discursos no deslocamento político da fala pública, na deslegitimação de espaços, no apagamento da memória, no reforço das desigualdades, na reconfiguração tecnológica educacional e na estigmatização da condição humana.

Já a segunda parte, denominada Uso e contato linguístico, com abordagens teóricas que perpassam a mudança e a norma linguística, a Sociolinguística e Dialetologia, Linguística Textual, Políticas Linguísticas e Linguística Histórica, reúne também seis textos que problematizam e evidenciam o preconceito da língua, o funcionamento social a partir da análise do purismo linguístico, a ocorrência dialetal, o uso dos conectores da língua na argumentação, os estudos sobre a Língua de Sinais (LIBRAS) e o contato linguístico.

Mónica Zoppi Fontana dá início às discussões com $A$ vontade do povo, a partir dos embates entre o amor à língua e à política "para uma conjuntura em que os discursos de ódio e as práticas institucionais de necropolítica governam" (FONTANA, 2020, p. 21). A autora, a partir da Análise do Discurso de linha francesa, proposta por Michel Pêcheux, reflete sobre as discursividades presentes na decisão do Ministério da Educação (MEC) de aplicar cortes no repasse de recursos às universidades federais, reduzindo seu orçamento. As matérias jornalísticas e os vídeos disponibilizados pelo governo nas redes sociais 
apontam para uma desestabilização da fala pública quando, numa espécie de jogo ideológico, desregulam a ordem do discurso e deslocalizam o sujeito enunciador a um espaço de equívocos.

"O palco e a rua no discurso sobre o sujeito transexual: lugares possíveis", de Fábio de Oliveira Vargas e Vanise Medeiros, discute os lugares determinados historicamente do sujeito transexual. A partir da Análise do Discurso de Michel Pêcheux, implicada no reconhecimento da construção dos processos semânticos acontecerem no transcursar da história, os autores identificam esse processo associado aos sujeitos transexuais em nosso país como bastante restrito, delegado ao palco, remetendo ao teatro, e às ruas, remetendo à marginalidade e à prostituição. Nesse sentido, a discussão evidencia a necessidade de os sujeitos transgêneros ocuparem todos os ambientes sociais, validando seu local de fala enquanto sujeitos, em suas múltiplas facetas identitárias.

No texto Dos discursos sobre a loucura na 'cidade dos loucos e das rosas': um percurso de pesquisa, Valéria Bergamini, Silmara Dela Silva e Olimpia Maluf-Souza demonstram o poder de opressão dos hospícios no município de Barbacena (MG), na institucionalização do discurso da loucura como uma ideologia econômica dominante. De forma sensível e mobilizando aspectos da Análise do Discurso de Michel Pêcheux e contribuições a partir dos trabalhos de Eni Orlandi, as autoras "analisam o modo como se constituem efeitos de sentidos para o chamado Holocausto Brasileiro, após a reforma Psiquiátrica no município de Barbacena, Minas Gerais, designado como cidade dos loucos e das rosas" (BERGAMINI; SILVA; MALUF-SOUZA, 2020, p. 59).

$\mathrm{O}$ quarto artigo da obra, A politecnia: conceito (inter)incompreendido na educação profissional brasileira, de Elayne Silva de Souza, Del Carmem Daher e Maria Cristina Giorgi, o mais extenso, a propósito, pontua os discursos sobre o conceito de politecnia, a partir do decreto $n^{\circ} 5.154 / 2004$ e a da Lei $n^{\circ} 11.892 / 2008$, concebendo-os em suas construções históricas. Amparadas nos postulados da Análise do Discurso, especificamente relacionado aos aspectos da semântica global de Dominique Maingueneau, as autoras revelam o embate do Ensino Médio Técnico entre atender à demanda de acesso ao trabalho e à continuidade dos estudos. A discussão revelase ainda mais necessária àqueles que compreendem, efetivamente, o 
conceito de politecnia inscrito na história que, por um lado, garante a formação integrada, concomitante e subsequente do sujeito; mas, por outro, abre espaço para uma concepção fragmentada de educação, conhecimento e cultura reforçada pelo materialismo do mercado de trabalho.

Quanto ao texto Ambiente virtual de aprendizagem: interações possíveis?, Silvia Maria de Sousa e Aparecida Maria Xenofonte de Pinho estabelecem uma reflexão sobre as práticas didáticas e as interações que elas suscitam no contexto virtual, a partir da perspectiva da Semiótica Discursiva, mas, sob os regimes de interação propostos por Eric Landowski. Nesse sentido, é analisado um Ambiente Virtual de Aprendizagem de uma licenciatura em Letras a distância de um Instituto Federal, concluindo, as autoras, "que o projeto de transformar o ensino em programação, substituir professores por plataformas e esperar dos alunos um leque de reações antecipadamente previstas [...] estará fadado ao fracasso" (SOUSA; PINHO, 2020, p. 142) - assertiva necessária, especialmente no contexto de neoliberalização do ensino, intensificado pela pandemia atual.

Para fechar a primeira parte da obra, a emocionante pesquisa Abandono afetivo e estigmatização: realidade dos idosos residentes em instituições de longa permanência no Brasil, de Isabel Cristina Adão Schiavon e José Carlos Gonçalves, retrata os discursos de profissionais da saúde relacionados ao cuidado com o idoso institucionalizado, no momento do banho. Por meio da Análise Sociointeracional do Discurso e a Análise da Conversa Etnometodológica, os estigmas decorrentes da idade são ressignificados através da fala das cuidadoras, propondo "constantemente à idosa uma revisão de sua identidade, gerando tensão constante entre identidade visual e real [...], e negando a estigmatização" (SCHIAVON; GONÇALVES, 2020, p. 155). Chega a ser ferina a naturalização da incapacidade do autocuidado como algo próprio da idade avançada presente nos discursos dos idosos atendidos em instituições de longa permanência no Brasil, muito embora, a pesquisa revele, por parte das cuidadoras, uma sensibilização quanto às relações humanas presentes nos diálogos observados.

$\mathrm{O}$ texto de Marcos Bagno que abre oportunamente a segunda parte desta obra, Erro de português: de onde vem essa ideia? Formação docente para uma educação linguística democrática, ratifica a tese do autor de que "nada na língua é por acaso", segundo a qual o fenômeno 
linguístico pode ser perfeitamente explicável a partir de argumentos sólidos e, por conseguinte, o preconceito linguístico termina fruto de fatores muito mais sociais e ideológicos - reflexos de um longo processo de exploração colonial - do que puramente da língua. $\mathrm{O}$ autor explica, ainda, a ideia de erro a partir de três conjuntos de reações sociais: os fenômenos de mudança linguística, os fenômenos de conservação de formas antigas e os fatores de natureza sociocultural, ideológica:

A forma como a noção de "erro de português" se cristalizou no Brasil reflete muito da formação histórica e da estrutura social do nosso tempo. Combater essas ideias retrógradas é a parte que nos toca, como educadoras, dentro do amplo espectro maior da luta por um país menos desigual e mais justo (BAGNO, 2020, p. 183).

Nesse sentido, o conhecimento linguístico, principalmente na escola, deve ser conduzido a partir de seus diferentes contextos de produção, sem marginalizar um ou outro uso da língua.

$\mathrm{O}$ artigo seguinte, $O$ purismo linguístico em português e em espanhol, de Xoán Carlos Lagares, é uma análise do funcionamento social da norma linguística quanto ao discurso de purismo linguístico em português e em espanhol. Por meio do conceito de dinâmica normativa, proposto por esse mesmo autor, ele "enfatiza o caráter político e não simplesmente técnico do processo padronizador [...] em que estão implicadas polêmicas sobre a forma de construir espaços linguísticos e comunidades e a disputa do seu controle" (LAGARES, 2020 , p. 187). Esse autor chama a atenção para o conflito social com a norma, porque evidencia relações de poder e de autoridade e uma atitude purista da língua só expõe medidas coercitivas. Sendo assim, purismo linguístico e conservadorismo social se equivalem.

Edila Vianna da Silva e Francisco de Assis Moreira, no artigo Conservação de aspectos linguísticos e culturais em região da Zona da Mata mineira, identificam ocorrências de itens lexicais do dialeto caipira ainda presentes na linguagem falada nos municípios de Silveira e Dores do Turvo, em Minas Gerais. Apoiado na Sociolinguística e Dialetologia, o trabalho recorre à referência da obra de Amadeu Amaral em $O$ dialeto caipira - justificando o uso do termo, considerado por alguns estudiosos, como transportador de uma acepção negativa -, para 
observar o léxico de uma determinada localidade e o que ele conserva a respeito das memórias sócio histórica e linguística-cultural. A partir das entrevistas empreendidas na pesquisa, verificou-se o impacto visível na linguagem, pela resistência de itens lexicais caipiras, preservados em alguns momentos e alterados em outros, enquanto resultado de contextos relacionados ao gênero, idade, geografia e cultura de inscrição dos falantes.

$O$ uso dos conectores e articuladores de coesão na construção do texto à luz da semântica argumentativa, texto de Roberta Vecchi Prates, problematiza, à luz da Linguística Textual e da Semântica Argumentativa, a forma como os falantes têm utilizado os conectivos na construção do texto. Esse uso, revela o artigo, está pautado em maior grau na própria força argumentativa e não "apenas como liames relacionais como assevera a gramática tradicional” (PRATES, 2020, p. 248). Os textos analisados de estudantes do $3^{\circ}$ ano do Ensino Médio/Técnico do IF Sudeste MG - campus Rio Pomba, corpus dessa pesquisa, atestam "as relações de sentido instanciadas por meio dos conectores e articuladores de coesão [...] [e] auxiliam os mais diversos objetivos comunicacionais, a considerar o [...] engajamento [...] [propostos por] seus interlocutores" (PRATES, 2020, p. 247).

No penúltimo texto dessa obra, A responsabilidade social das universidades públicas brasileiras nas pesquisas sobre glotopolítica, Stela Cabral e Telma Pereira alvitram uma maior visibilidade ao desenvolvimento de estudos sobre a Língua de Sinais, reconhecendo a universidade como agente do processo de inclusão e divulgação dessa glotopolítica, que considera "os diferentes campos e atores sociais envolvidos na gestão de línguas, bem como nas decisões tomadas em menores instâncias" (CABRAL; PEREIRA, 2020, p. 255). A partir de estudos de Política Linguística e glotopolítica, as autoras inscrevem no cenário acadêmico temas por vezes negligenciados em tal atmosfera, a exemplo de questões relativas à LIBRAS. Promover cada vez mais pesquisas em torno das línguas no Brasil é o caminho para não haver o apagamento das "lutas e disputas existentes na sociedade que estavam refletidas e representadas na língua" (CABRAL; PEREIRA, 2020, p. 262), configurando, assim, uma ação interventiva da glotopolítica.

Por fim, Marcionilo Euro Carlos Neto e Mônica Maria Guimarães Savedra, em Koroniago: uma coiné nipobrasileira, por meio da Linguística Histórica, apresentam/discutem a variedade linguística 
estabelecida a partir do contato entre brasileiros e imigrantes japoneses. De acordo com tais autores, destaca-se, nesse contexto, a evidência de uma identidade híbrida, expressa na interação entre os povos envolvidos na situação de contato; o processo linguístico lento e gradual (coneização); e a indeterminação de uma fronteira linguística "entre os fatores étnicos nipônicos e brasileiros” (NETO; SAVEDRA, 2020, p. 281) - por isso, a palavra nipobrasileira grafada sem o hífen. O estudo desvela, de modo significativo, a importância e o caráter "da formação linguístico-identitária dos imigrantes japoneses e seus descentes em nosso país" (NETO; SAVEDRA, 2020, p. 292).

Silmara Dela Silva e Mônica Maria Savedra, professoras da PosLing - UFF, não se furtam ao compromisso da educabilidade ao propor uma seleção de textos que, para além da palavra, instigam à pesquisa aqueles que se mostram predisponentes para a atuação comprometida e séria. É mais uma obra que entra para o rol das pesquisas em linguagem por, em especial, no atual contexto desfavorável para a pesquisa em nosso país, trazer à tona pesquisadoras e pesquisadores que se mostram engajados com o contexto social do qual suas pesquisas emergem.

\section{Referências:}

BAGNO, M. Erro de português: de onde vem essa ideia?. In: DELA SILVA, Silmara; SAVEDRA, Mônica Maria Guimarães. (Org.).. (Org.). Estudos de linguagem e compromisso social. Campinas: Pontes, 2020, v. 1, p. 161-184.

BERGAMINI, V. ; Dela Silva, S. ; MALUF-SOUZA, O. Dos discursos sobre a loucura a Cidade dos Loucos e das Rosas: um percurso de pesquisa. In: DELA SILVA, Silmara; SAVEDRA, Mônica Maria Guimarães. (Org.). Estudos de linguagem e compromisso social. Campinas-SP: Pontes Editores, 2020, v. 1, p. 59-83.

CABRAL, S. ; PEREIRA, T. A responsabilidade social das universidades públicas brasileiras nas pesquisas sobre glotopolítica. In: DELA SILVA, Silmara; SAVEDRA, Mônica Maria Guimarães. (Org.). Estudos de Linguagem e compromisso social. Campinas: Pontes, 2020. v. 1.

DELA SILVA, Silmara; SAVEDRA, Mônica Maria Guimarães. (Org.). Estudos de linguagem e compromisso social. Campinas, SP: Pontes Editora, 2020. 306 p. 
LAGARES, X. C. O purismo linguístico em português e espanhol. In: DELA SILVA, Silmara; SAVEDRA, Mônica Maria Guimarães. (Org.). Estudos de Linguagem e compromisso social. 1ed. Campinas: Pontes Editora, 2020, v. 1, p. 185-202.

NETO, M. E. C.; SAVEDRA, M. M. G. . Koroniago: Uma coiné nipobrasileira. In: Silmara Dela Silva; Mônica Maria Guimarães Savedra. (Org.). Estudos de Linguagem e compromisso social. Campinas: Pontes, 2020, v. 1, p. 265-297.

PRATES, R. V. O uso dos conectores e articuladores de coesão na construção do texto à luz da semântica argumentativa. In: DELA SILVA, Silmara; SAVEDRA, Mônica Maria Guimarães. (Org.). Estudos de Linguagem e compromisso social. Campinas: Pontes Editora, 2020, v. 1

SILVA, E. V.; MOREIRA, F. A. Conservação de aspectos linguísticos e culturais em região da Zona da Mata mineira. In: DELA SILVA, Silmara; SAVEDRA, Mônica Maria Guimarães. (Org.). Estudos de Linguagem e compromisso social. Campinas: Pontes Editora, 2020, v. 1

SCHIAVON, I. C. A; GONCALVES, J. C. Abandono afetivo e estigmatização: realidade dos idosos residentes em instituições de longa permanência no Brasil. In: DELA SILVA, Silmara; SAVEDRA, Mônica Maria Guimarães. (Org.). Estudos de linguagem e compromisso social. Campinas: Pontes Editores, 2020, v. 1, p. 145157.

SOUZA, E. S.; DAHER, D. C.; GIORGI, M. C.. A politecnia: conceito (inter)incompreendido na educação profissional brasileira. In: DELA SILVA, Silmara; SAVEDRA, Mônica Maria Guimarães. (Org.). Estudos de linguagem e compromisso social. Campinas: Pontes Editora, 2020, v. 1 p. 85-123.

SOUSA, S. M.; PINHO, A. M. X.. Ambiente virtual de aprendizagem: interações possíveis? In: DELA SILVA, Silmara; SAVEDRA, Mônica Maria Guimarães. (Org.). Estudos de Linguagem e compromisso social. Campinas: Pontes, 2020, v. 01, p. 124-144.

VARGAS, F.; MEDEIROS, V. O. O palco e a rua no discurso sobre o sujeito transexual: lugares possíveis. In: DELA SILVA, Silmara; SAVEDRA, Mônica Maria Guimarães. (Org.). Estudos de linguagem e compromisso social. Campinas: Pontes, 2020, v. 1, p. 41-57. 
ZOPPI FONTANA, M. G. A vontade do povo. In: DELA SILVA, Silmara; SAVEDRA, Mônica Maria Guimarães. (Org.). Estudos de linguagem e compromisso social. Campinas: Pontes, 2020, v. 1, p. 2140.

\section{Notas}

* Mestrando em Letras pela Universidade do Estado de Mato Grosso (UNEMAT).

** Doutora em Educação pela Universidade Federal do Rio Grande do Sul (UFRGS) e Docente do Programa de Pós-Graduação em Letras da Universidade do Estado de Mato Grosso (UNEMAT). 